\title{
Hypertrophic Obstructive Cardiomyopathy and Pregnancy: A Clinical Case Series
}

\author{
Anupama Hari ${ }^{1}$ Momina Zulfeen ${ }^{1}$ Sindhu Madhavaneni ${ }^{1}$
}

\begin{abstract}
Address for correspondence Momina Zulfeen, MS, Senior Resident, Department of Obstetrics and Gyanecology, Gandhi Medical College, Secunderabad 500003, Telangana, India (e-mail: mominazulfeen@gmail.com).
\end{abstract}

\begin{abstract}
Hypertrophic obstructive cardiomyopathy (HOCM) is a primary myocardial disorder caused by mutations in several different genes coding for contractile proteins. Although HOCM is being increasingly diagnosed in women of reproductive age due to widespread use of echocardiography and screening programs, there are fewer studies of HOCM in pregnancy owing to the rarity of the disease and poor recognition. Our clinical case series includes five cases of hypertrophic cardiomyopathy and its management. The authors describe five women presenting with $\mathrm{HOCM}$ with varied symptoms. All patients except one had favorable outcome. Neonatal outcome was good except for a second trimester intrauterine fetal demise. Intensive care unit (ICU) requirement ranged from 5 to 10 days. Two cases were established cases of HOCM. Pain relief was adequate with narcotics, although regional anesthesia was given to one with HOCM with corrected obstruction. No hypotension or deterioration was noted. Although it is believed that HOCM is well tolerated in pregnancy, it is important to have the diagnosis since management differs. Inadvertent regional anesthesia or

Keywords

- cardiomyopathy

- hypertrophic

- pregnancy hypotension due to blood loss or heightened sympathetic response to pain may prove detrimental to these patients. Maternal and fetal outcome are good. Prenatal routine echocardiography screening may prove efficient in identifying high-risk women, for early referral and better management.
\end{abstract}

\section{Introduction}

Hypertrophic obstructive cardiomyopathy (HOCM) is a primary myocardial disorder caused by mutations in several different genes coding for contractile proteins. It can occur sporadically or in an autosomal dominant pattern of inheritance. ${ }^{1}$ Although HOCM is being increasingly diagnosed in women of reproductive age due to widespread use of echocardiography and screening programs, there are fewer studies of HOCM in pregnancy owing to the rarity of the disease and poor recognition. Such studies will help establish guidelines for management of pregnancies with HOCM.

Our clinical case series includes five cases of hypertrophic cardiomyopathy admitted to the labor ward in maternity block, Gandhi Medical College.

\section{Case Series}

Case 1

A 32-year-old gravida 3 para 2 live 2 with term gestation presented with class III dyspnea and was diagnosed with HOCM. There were no previous medical records available. There was no family history of cardiac disease. On examination, she was dyspneic on less than ordinary physical activity with tachycardia of 110 beats/min (bpm). Blood pressure and oxygen saturation were normal. Grade 4/6 systolic murmur was heard maximum during handgrip maneuver. An electrocardiogram (ECG) showed sinus tachycardia with left axis deviation and lateral ST-T wave abnormality suggestive of left ventricular (LV) hypertrophy. Her two-dimensional echocardiography (2dEcho) revealed HOCM with asymmetrical 
septal hypertrophy (ASH) and grade 3 systolic anterior motion (SAM), left ventricular outflow tract (LVOT) with resting gradient of $80 \mathrm{~mm} \mathrm{Hg}$ with LVOT obstruction, mitral valve prolapse with grade 2 mitral regurgitation (MR), mild aortic regurgitation (AR), and ejection fraction (EF) $52 \%$.

The patient was started on oral metoprolol $12.5 \mathrm{mg}$, and noninvasive monitoring was done. Labor was spontaneous in onset 48 hours after admission, and the patient had an assisted vaginal delivery with outlet forceps. Pain relief was given with narcotics. Newborn was a male, weighing $2.52 \mathrm{~kg}$, with Apgar scores 8 and 9 at 1 and 5 minutes, respectively. Neonatal screening was normal. Postnatal period was uneventful, and the total duration of intensive care unit (ICU) stay was 5 days. She was discharged in a stable condition with metoprolol $12.5 \mathrm{mg}$ and was advised further follow-up.

\section{Case 2}

A 25-year-old unbooked gravida 2 para 1 live 1 at 24 weeks gestation presented with grade 3 dyspnea and was diagnosed with HOCM. There was no family history of cardiac disease. She was previously symptomatic with New York Heart Association grade 2 (NYHA2), but was not evaluated. On examination, she was dyspneic on less than ordinary physical activity with tachycardia of $114 \mathrm{bpm}$. Blood pressure and oxygen saturation were normal. An ECG showed sinus tachycardia with LV strain pattern. 2dEcho showed HOCM with ASH and grade 3 SAM, LVOT gradient of $90 \mathrm{~mm} \mathrm{Hg}$ at rest, and severe MR with an EF of 59\%. Ultrasound confirmed intrauterine death with anhydramnios. Previous antenatal scans and anomaly scan were not available. Pregnancy was terminated by combined mechanical dilatation of cervix with Foley balloon and intracervical prostaglandin E2 (PGE2) gel. The patient delivered 48 hours after induction. Cardiac status did not worsen, and the patient was managed conservatively with $\beta$-blocker oral metoprolol succinate $12.5 \mathrm{mg}$, which was titrated up to $25 \mathrm{mg} /$ day, and extended-release verapamil 80 $\mathrm{mg} /$ day. She required an ICU stay of 7 days.

\section{Case 3}

A 28-year-old primigravida of 38 weeks gestation and a known case of HOCM with labile LVOT obstruction NYHA grade 1 presented with worsening dyspnea of grade 3 . She had a previous history of atrial arrhythmia 3 years back and was presently on metoprolol succinate $12.5 \mathrm{mg} /$ day. An ECG showed mild LV strain pattern, sinus rhythm. 2dEcho showed HOCM with LVOT gradient of $80 \mathrm{~mm} \mathrm{Hg}$ at rest with mild MR and grade 2 SAM, EF 50\%. She delivered a female baby of $3 \mathrm{~kg}$ by vacuum-assisted vaginal delivery. Apgar scores were 8 and 9 at 1 and 5 minutes, respectively. Neonatal screening was normal. The patient developed dizziness a few hours postpartum. An ECG showed atrial fibrillation with ventricular rate of $120 \mathrm{bpm}$. The patient remained hemodynamically stable. Pharmacological cardioversion was done with optimal dose of amiodarone infusion for 24 hours, and thromboprophylaxis was given with low molecular weight heparin (LMWH) $40 \mathrm{mg}$ twice daily. The patient was put on implantable cardioverter-defibrillator for primary prevention of sudden cardiac death. Further course in the hospital was uneventful, required ICU care for 10 days. She was discharged with continuation of $\beta$-blocker metoprolol succinate $25 \mathrm{mg} /$ day and LMWH 40 mg twice daily; follow-up was suggested.

\section{Case 4}

A 30-year-old gravida 5 para 4 live 4 with 39 weeks gestation was diagnosed with HOCM with labile obstruction on routine cardiac screening. ECG was normal. 2decho showed HOCM with ASH and LVOT gradient of $43 \mathrm{~mm} \mathrm{Hg}$ during Valsalva, fair LV function, and trivial TR/no pulmonary arterial hypertension. She delivered a female baby of $2.84 \mathrm{~kg}$ by normal vaginal delivery. Apgar score was 9 at 1 and 5 minutes. She had an uneventful course in the hospital. ICU admission was required for a day for observation during delivery, and she was discharged healthy after 5 days.

\section{Case 5}

A 20-year-old was primigravida of 39 weeks gestation and a known case of HOCM NYHA1 from 13 years of age. She presented in early labor with grade 2 dyspnea. The patient had undergone septal ablation for severe LV tract outflow obstruction at 13 years of age. She had previously been on propranolol and was shifted to metoprolol $12.5 \mathrm{mg}$ during pregnancy. Antenatal visits were regular and uneventful. ECG was normal with sinus rhythm of $86 \mathrm{bpm}$. 2decho showed LVH, mild asymmetric septal hypertrophy with fair LV function with no resting obstruction. LVOT gradient of 35 $\mathrm{mm}$ on Valsalva with EF of $65 \%$. The patient opted epidural analgesia for pain relief. No hypotension or dyspnea was noted. She delivered a male baby of $3.22 \mathrm{~kg}$ by a vacuumassisted vaginal delivery. Apgar scores were 8 and 9 at 1 and 5 minutes, respectively. Post-natal period was uneventful. She was discharged healthy 3 days later with continuation of $\beta$-blocker metoprolol $12.5 \mathrm{mg} /$ day after 3 days.

\section{Discussion}

Cardiomyopathy is a disease of the heart muscle. The traditional classification is of a triad of dilated, restrictive, and hypertrophic types. ${ }^{2}$ In the developed countries, cardiovascular disease is the most common cause of pregnancy-related deaths with cardiomyopathy accounting for over $11 \%$ of maternal deaths in the United States. The most common cause is peripartum cardiomyopathy. Other causes include HOCM and pre-existing dilated cardiomyopathy. ${ }^{1}$ With a low incidence of 0.1 to $0.5 \%^{3}$ and mostly asymptomatic, HOCM is often undiagnosed or missed in the community, hence may manifest for the first time during pregnancy, posing greater difficulty in diagnosis due to altered physiology.

Hypertrophic obstructive cardiomyopathy has been defined by the European Society of Cardiology (ESC) as the presence of increased LV wall thickness that is not solely explained by abnormal loading conditions. ${ }^{4}$ Myocardial disarray and fibrosis are the histological hallmarks of the disease. Both the extent and localization of the hypertrophy are variable with asymmetric septal hypertrophy being the most common phenotype. LVOT obstruction is present in $\sim 70 \%$, and the diagnosis is primarily made by echocardiography. 
The phenotypic expression of the disease is very heterogeneous. The clinical course may range from an asymptomatic status to highly symptomatic, functionally limited condition with heart failure and malignant arrhythmias. The LVOT obstruction is often associated with MR, mostly due to SAM of the mitral valve, although intrinsic abnormalities of the mitral valve apparatus also contribute. Dyspnea and chest pain are the most frequent symptoms and relate to the pathophysiological impact of the diastolic dysfunction. Atrial fibrillation is the most common arrhythmia and is poorly tolerated with high risk of thromboembolism. A risk of sudden death is suggested by a family history of syncope, non-sustained ventricular tachycardia, and hypotension with exercise. ${ }^{5}$

During pregnancy, plasma volume and cardiac output increase. The increase in cardiac output in the first and second trimesters is achieved by a larger stroke volume, while later in pregnancy, there is an increase in heart rate. The additional volume load of pregnancy causes enlargement of the ventricular cavity, which theoretically might reduce the LVOT obstruction; however, the increased cardiac output tends to counteract this effect, and the LVOT gradient will increase with advancing gestation. The same volume loading increases distension of the left atrium and thereby risk of atrial fibrillation. ${ }^{3,5,6}$ At the time of delivery, cardiac output increases further secondary to auto-transfusion of blood from the contraction of uterus and increased catecholamine levels. There is also an increase in the heart rate secondary to blood loss, pain, and stress, while the expulsive efforts during delivery tend to diminish venous return. These physiological changes may lead to an increase in LVTO gradient and shorten the diagnostic filling period, thereby increasing the risk of pulmonary edema.

Hypertrophic obstructive cardiomyopathy is considered a World Health Organization (WHO) class II or III risk lesion suggestive of moderate morbidity. ${ }^{7}$ Pregnancy is contraindicated in significant impairment of systolic function (LVEF $<40 \%$ ) or if there is severe symptomatic LVOT obstruction. In the latter group, pregnancy may be possible after relief of obstruction by surgery or alcohol septal ablation. The goal of management is to lessen or eliminate the LVOT gradient through negative inotropy. Pharmacological regimens include $\beta$-blockers, calcium antagonists and disopyramide. Alcohol septal ablation and surgical myectomy are other options. ${ }^{8}$ Metoprolol is the preferred $\beta$-blocker in pregnancy. Verapamil may be used with caution. ${ }^{9}$ While vaginal delivery is the preferred mode of delivery, caesarean section is reserved for obstetric indications.

Epidural and spinal anesthesia must be administered cautiously in women with severe LVOT obstruction due to consequent vasodilatation and hypotension and single shot spinal anesthesia be avoided. However, the benefits of pain reduction and reduced sympathetic stimulation may outweigh the disadvantages. ${ }^{10}$ Heart rhythm and blood pressure should be monitored noninvasively, and invasive monitoring such as pulmonary artery Swan-Ganz catheter is best avoided due to risks of thromboembolism and arrhythmias. Noninvasive cardiac monitoring may be accomplished by transthoracic echocardiography. Oxytocin is given slow intravenously (IV) up to five units postpartum. The fluid shifts associated with delivery and immediately afterward increase the risk of pulmonary edema; therefore, close monitoring is important for at least 24 hours. ${ }^{11}$

In this case series of five cases of HOCM in pregnancy observed in our hospital, significant characteristics have been listed in - Table 1 .

All patients except one had favorable outcome. Neonatal outcome was good except for a second trimester intrauterine fetal demise. ICU requirement ranged from 5 to 10 days. Two cases were established cases of HOCM. Pain relief was adequate with narcotics, although regional anesthesia was given to one with HOCM with corrected obstruction. No hypotension or deterioration was noted.

Although it is believed that HOCM is well tolerated in pregnancy, it is important to have the diagnosis since the management may differ. Inadvertent regional anesthesia or hypotension due to blood loss or heightened sympathetic response to pain may prove detrimental to these patients. Patients at high risk of sudden cardiac death are those with previous episodes of sustained ventricular tachycardia or those who have strong family history of cardiac death. ${ }^{8}$ Given the gravity of such grave complications, pre-pregnancy diagnosis and risk assessment are important.

The ESC guidelines ${ }^{12,13}$ on the management of cardiovascular disease during pregnancy advise that a risk assessment is performed using the modified WHO classification. Drenthen et a $l^{14}$ postulated predictors for increased risk of complications in pregnancy, which include symptoms pre-pregnancy, LVOT obstruction, arrhythmias, and impaired LV function. In this case series, only one had post-partum arrhythmias, which could be attributed to her previously symptomatic nature and severe LVOT. A pre-pregnancy evaluation and preplanned ICD for defibrillation could have been useful.

Thaman et $\mathrm{al}^{15}$ studied 127 women with HOCM and concluded that HOCM is generally well tolerated in pregnancy; the presence of significant LVOT did not affect maternal outcome. Although the outcome was favorable, the study was limited by its retrospective nature. The mean LVOT in the study was lower $(25 \mathrm{~mm} \mathrm{Hg}$ ). The study also could not evaluate the effect of regional anesthesia in HOCM.

In the study by Autore et al, clinical deterioration occurred more with LVOT obstruction than without. The reported total mortality in women with HOCM was 10 per 1,000 live births, which were higher compared with general population; however, the absolute maternal mortality was low and confined to high-risk women such as those who were symptomatic before pregnancy. ${ }^{8}$ Thus, the need for pre-pregnancy diagnosis and risk evaluation is important to predict and ensure good management.

\section{Conclusion}

Hypertrophic obstructive cardiomyopathy is an uncommon yet serious cardiac disease due to its sudden complications and occult nature, more so significant in developing countries such as India. Although well tolerated in pregnancy, 
Table 1 Characteristics of the cases of HOCM and pregnancy

\begin{tabular}{|c|c|c|c|c|c|}
\hline Finding & Case 1 & Case 2 & Case 3 & Case 4 & Case 5 \\
\hline Age & 32 & 25 & 28 & 30 & 20 \\
\hline Gravida & 3 & 2 & 1 & 5 & 1 \\
\hline Previously diagnosed & No & No & Yes & No & Yes \\
\hline $\begin{array}{l}\text { NYHA grade at } \\
\text { presentation }\end{array}$ & 3 & 3 & 3 & 1 & 2 \\
\hline Worsening of NYHA & No & No & Yes & No & Yes \\
\hline $\begin{array}{l}\text { Symptoms before } \\
\text { pregnancy }\end{array}$ & No & Yes & Yes & No & Yes \\
\hline History of arrhythmias & No & No & Yes & No & No \\
\hline $\begin{array}{l}\text { History of LV } \\
\text { dysfunction }\end{array}$ & No & No & No & No & No \\
\hline $\begin{array}{l}\text { Management before } \\
\text { pregnancy }\end{array}$ & - & - & $\begin{array}{l}\text { Septal resection and } \\
\beta \text {-blockers }\end{array}$ & - & $\beta$-blockers \\
\hline LVOT gradient in $\mathrm{mmHg}$ & 80 & 90 & 120 & $\begin{array}{l}43 \text { on } \\
\text { Valsalva }\end{array}$ & 35 on Valsalva \\
\hline Mode of delivery & Vaginal & $\begin{array}{l}\text { Vaginal-second trimester } \\
\text { termination }\end{array}$ & Vaginal & Vaginal & vaginal \\
\hline Neonatal outcome & Good & $\begin{array}{l}\text { Second trimester } \\
\text { intrauterine fetal demise }\end{array}$ & Good & Good & Good \\
\hline Maternal complication & None & None & $\begin{array}{l}\text { Postpartum atrial } \\
\text { fibrillation }\end{array}$ & None & None \\
\hline Pain relief & Narcotics & Narcotics & Narcotics & Narcotics & Epidural analgesia \\
\hline
\end{tabular}

Abbreviations: LV, left ventricular; LVOT, left ventricular outflow tract; NYHA, New York Heart Association.

pre-pregnancy risk evaluation is important. Maternal and fetal outcome are good. Prenatal routine echocardiographic screening may prove efficient in identifying high-risk women, for early referral and better management.

\section{Conflicts of Interest}

None.

\section{References}

1 Deen J, Chandrasekaran S, Stout K, Easterling T. Heart disease in pregnancy. In: Gabbe SG, Niebyl JR, Simpson JL, et al, eds. Obstetrics: Normal and Problem Pregnancies. Haryana, India: RELX India Private Ltd (for Elsevier); 2017: 803-827

2 Lakdawala NK, Stevenson L, Loscalzo J. Cardiomyopathy and myocarditis. In: Jameson J, Fauci AS, Kasper DL, Hauser SL, Longo DL, Loscalzo J, eds. Harrison's Principles of Internal Medicine. 20th ed. New York, NY: McGraw-Hill; 2018: 1825-1843. Available at: http://accessmedicine.mhmedical.com/content. aspx?bookid=2129\&sectionid $=192029156$. Accessed August 01,2018

3 Verheugt CL, Uiterwaal CSPM, van der Velde ET, et al. The emerging burden of hospital admissions of adults with congenital heart disease. Heart 2010;96(11):872-878

4 Elliott PM, Anastasakis A, Borger MA, et al; Authors/Task Force members. 2014 ESC Guidelines on diagnosis and management of hypertrophic cardiomyopathy: the Task Force for the Diagnosis and Management of Hypertrophic Cardiomyopathy of the European Society of Cardiology (ESC). Eur Heart J 2014;35(39):2733-2779

5 Christiaans I, Birnie E, Bonsel GJ, et al. Manifest disease, risk factors for sudden cardiac death, and cardiac events in a large nationwide cohort of predictively tested hypertrophic cardiomyopathy mutation carriers: determining the best cardiological screening strategy. Eur Heart J 2011;32(9):1161-1170

6 Cardiovascular disorders. In: Cunningham F, Leveno KJ, Bloom SL, et al eds. Williams Obstetrics. 25th ed. New York, NY: McGraw-Hill; 2018: 948-975

7 Gersh BJ, Maron BJ, Bonow RO, et al; American College of Cardiology Foundation/American Heart Association Task Force on Practice; American Association for Thoracic Surgery; American Society of Echocardiography; American Society of Nuclear Cardiology; Heart Failure Society of America; Heart Rhythm Society; Society for Cardiovascular Angiography and Interventions; Society of Thoracic Surgeons. 2011 ACCF/AHA guideline for the diagnosis and treatment of hypertrophic cardiomyopathy: a report of the American College of Cardiology Foundation/American Heart Association Task Force on Practice Guidelines. J Thorac Cardiovasc Surg 2011;142(6):e153-e203

8 Autore C, Conte MR, Piccininno M, et al. Risk associated with pregnancy in hypertrophic cardiomyopathy. J Am Coll Cardiol 2002;40(10):1864-1869

9 Gilligan DM, Chan WL, Joshi J, et al. A double-blind, placebo-controlled crossover trial of nadolol and verapamil in mild and moderately symptomatic hypertrophic cardiomyopathy. J Am Coll Cardiol 1993;21(7):1672-1679

10 Ishiyama T, Oguchi T, Iijima T, Matsukawa T, Kashimoto S, Kumazawa T. Combined spinal and epidural anesthesia for caesarean section in a patient with hypert rophic obstructive cardiomyopathy. Anesth Analg 2003;96(2):626-633

11 Swan HJ, Ganz W, Forrester J, Marcus H, Diamond G, Chonette D. Catheterization of the heart in man with use of a flow-directed balloon-tipped catheter. N Engl J Med 1970;283(9):447-451

12 Regitz-Zagrosek V, Blomstrom Lundqvist C, Borghi C, et al; European Society of Gynecology (ESG); Association for European Paediatric Cardiology (AEPC); German Society for Gender Medicine (DGesGM); ESC Committee for Practice 
Guidelines. ESC Guidelines on the management of cardiovascular diseases during pregnancy: the Task Force on the Management of Cardiovascular Diseases during Pregnancy of the European Society of Cardiology (ESC). Eur Heart J 2011;32(24):3147-3197

13 Pieper PG. Pre-pregnancy risk assessment and counselling of the cardiac patient. Neth Heart J 2011;19(11):477-481
14 Drenthen W, Boersma E, Balci A, et al; ZAHARA Investigators. Predictors of pregnancy complications in women with congenital heart disease. Eur Heart J 2010;31(17):2124-2132

15 Thaman R, Varnava A, Hamid MS, et al. Pregnancy related complications in women with hypertrophic cardiomyopathy. Heart 2003;89(7):752-756 